\title{
Global challenges with scale-up of the integrated management of childhood illness strategy: results of a multi-country survey
}

\author{
Ameena E Goga ${ }^{1 *}$ and Lulu M Muhe ${ }^{2}$
}

\begin{abstract}
Background: The Integrated Management of Childhood Illness Strategy (IMCI), developed by WHO/UNICEF, aims to contribute to reducing childhood morbidity and mortality (MDG4) in resource-limited settings. Since 1996 more than 100 countries have adopted IMCI. IMCI case management training (ICMT) is one of three IMCI components and training is usually residential over 11 consecutive days. Follow-up after ICMT is an essential part of training. We describe the barriers to rapid acceleration of ICMT and review country perspectives on how to address these barriers.

Methods: A multi-country exploratory cross-sectional questionnaire survey of in-service ICMT approaches, using quantitative and qualitative methods, was conducted in 2006-7: 27 countries were purposively selected from all six WHO regions. Data for this paper are from three questionnaires (QA, QB and QC), distributed to selected national focal IMCI persons/programme officers, course directors/facilitators and IMCI trainees respectively. QC only gathered data on experiences with $\mathrm{IMCl}$ follow-up.

Results: 33 QA, 163 QB and 272 QC were received. The commonest challenges to ICMT scale-up relate to funding (high cost and long duration of the residential ICMT), poor literacy of health workers, differing opinions about the role of $\mathrm{IMCl}$ in improving child health, lack of political support, frequent changes in staff or rules at Ministries of Health and lack of skilled facilitators. Countries addressed these challenges in several ways including increased advocacy, developing strategic linkages with other priorities, intensifying pre-service training, re-distribution of funds and shortening course duration. The commonest challenges to follow-up after ICMT were lack of funding (93.1\% of respondents), inadequate funds for travelling or planning $(75.9 \%$ and $44.8 \%$ respectively), lack of gas for travelling (41.4\%), inadequately trained or few supervisors (41.4\%) and inadequate job aids for follow-up (27.6\%). Countries addressed these by piggy backing IMCI follow-up with routine supervisory visits.

Conclusions: Financial challenges to ICMT scale-up and follow-up after training are common. As IMCI is accepted globally as one of the key strategies to meet MDG4 several steps need to be taken to facilitate rapid acceleration of ICMT, including reviewing core competencies followed by competency-driven shortened training duration or 'on the job' training, 'distance learning' or training using mobile phones. Linkages with other 'better-funded' programmes e.g. HIV or malaria need to be improved. Routine Primary Health Care (PHC) supervision needs to include follow-up after ICMT.
\end{abstract}

\section{Background}

The Integrated Management of Childhood Illness Strategy (IMCI), developed by WHO and UNICEF, has been identified as a key strategy to meeting the fourth millennium development goal (MDG4). IMCI has three components, viz. case management training (ICMT),

\footnotetext{
* Correspondence: Ameena.Goga@mrc.ac.za

${ }^{1}$ Health Systems Research Unit, Medical Research Council, 1 Soutpansberg

Road, Pretoria, 0001 Pretoria, South Africa

Full list of author information is available at the end of the article
}

strengthening the health system and intensifying household and community behaviours to improve child health [1]. ICMT is presented as an 11-day course (usually residential) and teaches health care providers to manage sick children up to the age of 5 years, presenting to primary health care facilities with illnesses that account for major childhood morbidity and mortality. The course comprises six key modules and clinical practice. WHO recommends that $44.2 \%$ of course time is spent on clinical practice $1.2 \%$ on Introduction,

\section{C) Biomed Central}


20.9\% on Assess and Classify, 4.9\% on Identify Treatment, $11.6 \%$ on Treat the Child, $6.9 \%$ on Counsel the Mother, $6.9 \%$ on Sick Young Infant and 3.5\% on Follow-up. The IMCI management algorithms or charts are colour coded and each trained health care provider is provided with a chart booklet to use during consultations. Each ICMT course is facilitated by trained facilitators and a $1:<4$ facilitator: participant ratio is recommended.

Follow-up after training is an essential component of ICMT, as laid down in the IMCI information package [1]. The package describes follow-up after ICMT as an opportunity to reinforce skills acquired during training and solve problems encountered during IMCI implementation. The approach to follow-up developed by the WHO Department of Child and Adolescent Health and Development $(\mathrm{CAH})$, also serves as a bridge to ongoing district-level supervision.

ICMT has been shown to reduce under-five mortality [2] and to improve antimicrobial use in first level facilities [3].

Despite data on the effectiveness of IMCI in decreasing antimicrobial prescription by health workers, improving quality of care, child health indicators, quality of counselling provided to caregivers, and bed net use [3-10], current global coverage by IMCI-case management-trained health workers is low [11]. Furthermore recent data from South Africa showed that although health workers in South Africa were implementing IMCI, clinical assessments using IMCI were frequently incomplete - only $18 \%$ checked for all main symptoms [12]. Focus group discussions amongst health workers in South Africa also showed that although they found the training interesting, informative and empowering the training time was short and follow-up visits, though helpful, were often delayed resulting in no ongoing clinical supervision [13].

In view of the potential contribution that IMCI scaleup could have on childhood morbidity and mortality, and the dearth of documented information on how IMCI was actually being implemented globally we conducted a survey in 2006 to review the training approaches and methods used for IMCI case management, document challenges to rapid scale-up of ICMT, document how countries are addressing these barriers and explore country experiences with follow-up after ICMT. It was intended that this information be used to guide future approaches to ICMT.

The first two questions (reviewing training approaches and methods) have been addressed in a separate paper [14]. This paper reports the challenges to rapid ICMT scale-up, how countries have tried to address these, and country experiences with follow-up of IMCI trainees after ICMT.

\section{Methods}

\section{Study design and aims}

The data were obtained from a multi-country exploratory questionnaire survey of in-service IMCI training approaches using qualitative and quantitative methods (Table 1). The survey sought to review country adaptations of IMCI case management training, including adaptations to content and training methodologies (i.e. methods used in addition to the originally proposed written exercises, drills, video, photo booklet, role plays etc.) and to review variations in IMCI training approaches/course duration. The methodology is summarised below. More details are captured in the paper published by Goga et.al.[14]:

\section{Countries}

All six WHO regions were included so that a global picture of IMCI training approaches could be ascertained. WHO(CAH) purposively selected 27 countries (including one sub-national region - Kosovo). Country selection criteria included a high under-five mortality rate and presence of a WHO National Professional Officer (NPO).

\section{Study population}

The study population comprised purposively selected key informants from each purposively selected country. Key informants were the National focal person for IMCI (one per country) and/or WHO National Programme Officer for IMCI (one per country); IMCI course directors or facilitator (two per region/province within each country and IMCI-trained health workers. The course directors/facilitators should have ever directed/facilitated two or more IMCI case management courses.

\section{Study procedures}

Data were collected over 5-months (January-May 2007). Data for this analysis was obtained from Questionnaire A (QA) for the National IMCI focal person/NPO, Questionnaire $\mathrm{B}(\mathrm{QB})$ for course directors/facilitators and Questionnaire C (QC) for IMCI-trained health workers. All forms (questionnaires) gathered quantitative data, using tick boxes and closed-ended questions, and qualitative data using open-ended questions and projective techniques to gather information on current implementation of ICMT and attitudes towards current training approaches.

\section{Data analysis}

Data were entered using EpiData v3.1. Data from QA, QB and QC were captured separately. Data from QA were analyzed using EpiData Analysis v1.1 (Build 68). In addition each QA was scrutinised to glean important details about the nationally recognised courses offered. 
Table 1 Number Of Questionnaires Received From (\% Total Number Of Questionnaire Type), And Length Of Courses Offered, By Region And Country

\begin{tabular}{|c|c|c|c|c|c|}
\hline Region/Country & $\begin{array}{c}\text { Questionnaire } \\
\text { A } \\
n=33\end{array}$ & $\begin{array}{c}\text { Questionnaire } \\
\text { B } \\
n=163\end{array}$ & $\begin{array}{c}\text { Questionnaire } \\
\text { C } \\
n=272\end{array}$ & $\begin{array}{c}\text { Total no. } \\
\text { forms } \\
\text { from } \\
\text { country }\end{array}$ & $\begin{array}{l}\text { Adapted } \\
\text { duration of } \\
\text { ICMT } \\
\text { training } \\
\text { courses } \\
\text { offered }\end{array}$ \\
\hline \multicolumn{6}{|l|}{ AFRO } \\
\hline Eritrea & $2(6.1)$ & $10(6.1)$ & $6(2.2)$ & 18 & 14 days \\
\hline Ethiopia & $1(3.0)$ & $13(8.0)$ & $4(1.5)$ & 18 & 6 days \\
\hline Ghana & $1(3.0)$ & $9(5.5)$ & $22(8.2)$ & 32 & 3 days \\
\hline Kenya & $2(6.1)$ & $1(0.6)$ & $1(0.4)$ & 4 & $32 \mathrm{hrs}$ \\
\hline Madagascar & $3(9.1)$ & $7(4.3)$ & $2(0.7)$ & 12 & 3 days, $5-6$ days \\
\hline Niger & 0 & $7(4.3)$ & $13(4.8)$ & 20 & 6 days \\
\hline Nigeria & $1(3.0)$ & $4(2.4)$ & $13(4.8)$ & 18 & 5-6 days, 14 days \\
\hline United Republic of Tanzania & $1(3.0)$ & $15(9.2)$ & $31(11.5)$ & 47 & \\
\hline Uganda & $1(3.0)$ & $3(1.8)$ & $2(0.7)$ & 6 & 6 days, 14 days \\
\hline Zambia & 0 & $4(2.45)$ & $6(2.2)$ & 10 & 5-7 days \\
\hline \multicolumn{6}{|l|}{ WPRO } \\
\hline Cambodia & $2(6.1)$ & $5(3.1)$ & $16(6.0)$ & 23 & \\
\hline China & $1(3.0)$ & $18(11.0)$ & $15(5.6)$ & 34 & 5-7 days \\
\hline Fiji & $1(3.0)$ & $2(1.2)$ & $1(0.4)$ & 4 & 5 days \\
\hline Papua New Guinea & 0 & 0 & $5(1.9)$ & 5 & 5-7 days \\
\hline Vietnam & $1(3.0)$ & $24(14.7)$ & $71(26.4)$ & 96 & \\
\hline \multicolumn{6}{|l|}{ SEARO } \\
\hline India & $2(6.1)$ & $1(0.6)$ & $8(3.0)$ & 11 & 6-8 days \\
\hline Indonesia & $1(3.0)$ & $2(1.2)$ & $1(0.4)$ & 4 & 3 days, 5-6 days \\
\hline Nepal & $1(3.0)$ & 0 & 0 & 1 & 7 days \\
\hline \multicolumn{6}{|l|}{ EURO } \\
\hline Kazakhstan & $2(6.1)$ & $18(11.0)$ & $8(3.0)$ & 28 & 5-6 days \\
\hline Kosovo & $2(6.1)$ & $3(1.8)$ & $2(0.7)$ & 7 & 8-10 days \\
\hline Republic of Moldova & $2(6.1)$ & $9(5.5)$ & $13(4.8)$ & 24 & 12 days \\
\hline Uzbekistan & $3(9.1)$ & $5(3.1)$ & $29(9.7)$ & 37 & 4 days \\
\hline \multicolumn{6}{|l|}{ EMRO } \\
\hline Sudan & $1(3.0)$ & 0 & 0 & 1 & 5 days \\
\hline Jordan & 0 & 0 & 0 & & 5-7 days \\
\hline Egypt & 0 & 0 & 0 & & 5-7 days \\
\hline \multicolumn{6}{|l|}{ AMRO/PAHO } \\
\hline Peru & $1(3.1)$ & $2(1.2)$ & 0 & 3 & \\
\hline Nicaragua & $1(3.1)$ & $1(0.6)$ & $3(1.2)$ & 5 & 3-5 days \\
\hline
\end{tabular}

Data from QB and QC were imported into SAS version 9.1 (SAS Institute Inc., Cary NC, USA) for data management and analysis. Every $10^{\text {th }} \mathrm{QC}$ was selected to examine responses to pictures and words about IMCI.

\section{Results}

Table 1 shows the respondents by WHO region and country, and the change in duration of ICMT courses that each country is implementing. The course adaptations are discussed in a previous paper [14].

IMCI national focal persons (usually Ministry of Health staff), WHO National Professional Officers
(NPOs), course directors and facilitators mostly thought that IMCI training is not progressing as quickly and smoothly as planned.

\section{Perceived challenges to rapid scale-up of IMCI implementation}

Tables 2 and 3 show the challenges to IMCI implementation, as perceived by IMCI national focal persons/WHO NPOs, in general (Table 2) and by country (Table 3 ). Inadequate funding for training was perceived as a challenge to rapid scale-up of IMCI implementation by $71 \%$ of National Ministry of Health $(\mathrm{MOH}) / \mathrm{NPO}$ staff and 
Table 2 Perceived Challences To IMCI Implementation Globally

\begin{tabular}{|c|c|c|}
\hline & $\begin{array}{l}\text { Opinion of national Ministry of } \\
\text { Health/WHO National Professional Officer }\end{array}$ & $\begin{array}{l}\text { Opinion of Course } \\
\text { Directors/Facilitators }\end{array}$ \\
\hline \multicolumn{3}{|c|}{ POLITICAL } \\
\hline Lack of buy-in from national stakeholders & $14(45.2)$ & $38(23.5)$ \\
\hline Competing priorities & 7 (22.6) & $45(27.8)$ \\
\hline \multicolumn{3}{|c|}{ COST } \\
\hline Inadequate funds for training & $22(71.0)$ & $115(71.4)$ \\
\hline Too expensive & $23(74.2)$ & $55(34)$ \\
\hline Inadequate fund for printing modules & $12(38.7)$ & $62(38.3)$ \\
\hline Inadequate funds for refreshments & $11(35.5)$ & $52(32.1)$ \\
\hline Inadequate fund for copying video & $10(32.3)$ & $45(27.8)$ \\
\hline Prohibitive financial regulations & $13(41.9)$ & $43(26.5)$ \\
\hline \multicolumn{3}{|c|}{ HR } \\
\hline Lack of facilitators & $15(48.4)$ & $16(9.9)$ \\
\hline Lack of clinical instructors & $13(41.9)$ & $30(18.5)$ \\
\hline Demands too high caliber trainers & $11(35.5)$ & $38(23.5)$ \\
\hline \multicolumn{3}{|c|}{ OTHER } \\
\hline Inadequate facilities for copying the training video & $8(25.8)$ & $28(17.3)$ \\
\hline Long duration of course & $16(51.6)$ & $40(24.7)$ \\
\hline Lack of clinical materials. & $5(16.1)$ & $30(18.5)$ \\
\hline Lack of transport & $6(19.4)$ & $22(13.6)$ \\
\hline
\end{tabular}

course directors/facilitators. The commonest challenges to rapid ICMT scale-up, as perceived by IMCI national focal persons/NPOs, were the high cost of the course, inadequate funds for training and the long duration of the course (Tables 2 and 3).

The commonest barrier to scale-up, as perceived by course directors and facilitators was funding - specifically inadequate funds for/high cost of training. Qualitative work (open ended questions and projective techniques) highlighted five themes that emerged as barriers to rapid acceleration of IMCI case management training. These included strategic differences regarding the role of IMCI (vertical programme versus integrative approach), lack of political support, lack of human and material resources and time for IMCI implementation, poor reading ability of health workers (mainly in one country.. although other countries had addressed this by shortening the course and decreasing the reading) and mismatch between training needs and resources available (Figure 1).

\section{How challenges to ICMT scale-up have been addressed}

IMCI national focal persons and NPOs reported that challenges have been addressed in several ways, including increased advocacy for IMCI or creation of structural/administrative links between district or national functioning and IMCI, redistribution of funds or increased donor support, non-residential courses, shortening the duration of training and reducing the amount of reading during training (Figure 2).

\section{Challenges to Follow-up after Training}

According to respondents 48.7\% (95\% CI 35.9-61.7\%) of IMCI trainees are followed up within 6 weeks of IMCI case management training, and only $52.5 \%$ (IQR $44 \%$ ) of follow-up visits was linked with routine supervision. IMCI national focal persons/NPOs reported that the commonest challenges to IMCI follow-up after training were lack of funding for follow-up $(93.1 \%$ of respondents), inadequate funds for travel (75.9\%), inadequate funds for planning (44.8\%), lack of gas for travel (41.4\%), inadequately trained supervisors $(41.4 \%)$, an inadequate number of skilled supervisors $(41.4 \%)$ and inadequate job aids for follow-up (27.6\%).

IMCI national focal persons and NPOs reported several attitudes and experiences of follow-up after training. Whilst some facilitators and course directors accepted that follow-up is an integral part of training other facilitators and course directors seemed unable to plan for integration of IMCI-follow-up activities into their daily work (Figure 3 ). Similarly although IMCI trained health workers recognized the importance of follow-up a group of trained health workers also expressed despondency about follow-up, likening it to policing. They also highlighted the lack of skill or possible lack of human resources to undertake follow-up (Figure 3). Furthermore four main suggestions about follow-up after ICMT emerged, including viewing follow-up as an important part of IMCI training to strengthen practical skills and establish technical support, planning follow-up before a course is planned 
Table 3 Perceived Challenges To Rapid Scale-Up Of IMCI Implementation By Region And Country - Data From MoH/NPO

Inadequate Funds for training, printing, refreshments, Lack of material, transport,

accommodation, video

clinical instructors:

\begin{tabular}{|c|c|c|c|c|c|c|c|c|c|c|c|c|c|c|c|c|}
\hline REGION & COUNTRY & $\begin{array}{l}\text { Lack of buy- } \\
\text { in from } \\
\text { national } \\
\text { stakeholders }\end{array}$ & $\begin{array}{l}\text { Competing } \\
\text { priorities }\end{array}$ & $\begin{array}{l}\text { Long } \\
\text { duration } \\
\text { of } \\
\text { course }\end{array}$ & $\begin{array}{l}\text { Prohibitive } \\
\text { financial } \\
\text { regulations }\end{array}$ & $\begin{array}{c}\text { Too } \\
\text { expensive }\end{array}$ & Training & $\begin{array}{l}\text { Printing } \\
\text { Modules }\end{array}$ & Refreshments & Accommodation & $\begin{array}{l}\text { Copying } \\
\text { Video }\end{array}$ & $\begin{array}{l}\text { Clinical } \\
\text { materials }\end{array}$ & $\begin{array}{l}\text { Transport } \\
\text { to clinics }\end{array}$ & Trainers & $\mathrm{Cl}$ & $\begin{array}{l}\text { Course } \\
\text { demands } \\
\text { highly } \\
\text { skilled } \\
\text { trainers }\end{array}$ \\
\hline \multirow[t]{10}{*}{ AFRO } & Eritrea & & $\sqrt{ }$ & $\sqrt{ }$ & $\sqrt{ }$ & & $\sqrt{ }$ & $\sqrt{ }$ & $\sqrt{ }$ & & & & $\sqrt{ }$ & $\sqrt{ }$ & & \\
\hline & Ethiopia & & $\sqrt{ }$ & $\sqrt{ }$ & $\sqrt{ }$ & $\sqrt{ }$ & $\sqrt{ }$ & $\sqrt{ }$ & & & $\sqrt{ }$ & & $\sqrt{ }$ & $\sqrt{ }$ & $\sqrt{ }$ & $\sqrt{ }$ \\
\hline & Ghana & & & & & $\sqrt{ }$ & $\sqrt{ }$ & & & & & & & & $\sqrt{ }$ & $\sqrt{ }$ \\
\hline & Kenya $^{a}$ & $\sqrt{ }$ & & $\sqrt{ }$ & & $\sqrt{ }$ & $\sqrt{ }$ & & $\sqrt{ }$ & $\sqrt{ }$ & & $\sqrt{ }$ & & & $\sqrt{ }$ & $\sqrt{ }$ \\
\hline & Madagascar & $\sqrt{ }$ & & $\sqrt{ }$ & $\sqrt{ }$ & $\sqrt{ }$ & $\sqrt{ }$ & & $\sqrt{ }$ & $\sqrt{ }$ & & & & $\sqrt{ }$ & $\sqrt{ }$ & $\sqrt{ }$ \\
\hline & Niger & & $\sqrt{ }$ & $\sqrt{ }$ & $\sqrt{ }$ & $\sqrt{ }$ & $\sqrt{ }$ & & & & & & & & & 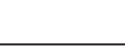 \\
\hline & Nigeria & $\sqrt{ }$ & & $\sqrt{ }$ & $\sqrt{ }$ & $\sqrt{ }$ & $\sqrt{ }$ & $\sqrt{ }$ & & & & & $\sqrt{ }$ & $\sqrt{ }$ & & $\sqrt{ }$ \\
\hline & $\begin{array}{l}\text { United Rep. } \\
\text { of Tanzania }\end{array}$ & $\sqrt{ }$ & & & & $\sqrt{ }$ & $\sqrt{ }$ & & & & $\sqrt{ }$ & & & $\sqrt{ }$ & & $\sqrt{ }$ \\
\hline & Uganda & $\sqrt{ }$ & & & & & $\sqrt{ }$ & $\sqrt{ }$ & $\sqrt{ }$ & & $\sqrt{ }$ & & & & & $\sqrt{ }$ \\
\hline & Zambia & & & & & & & & & & & & & & & \\
\hline \multirow[t]{5}{*}{ WPRO } & Cambodia & $\sqrt{ }$ & $\sqrt{ }$ & $\sqrt{ }$ & $\sqrt{ }$ & $\sqrt{ }$ & $\sqrt{ }$ & & & & & $\sqrt{ }$ & & $\sqrt{ }$ & $\sqrt{ }$ & $\sqrt{ }$ \\
\hline & China & & & $\sqrt{ }$ & & $\sqrt{ }$ & $\sqrt{ }$ & $\sqrt{ }$ & $\sqrt{ }$ & $\sqrt{ }$ & $\sqrt{ }$ & & & & & \\
\hline & Fiji & & $\sqrt{ }$ & $\sqrt{ }$ & & & $\sqrt{ }$ & & & & & & & $\sqrt{ }$ & $\sqrt{ }$ & \\
\hline & $\begin{array}{l}\text { Papua New } \\
\text { Guinea }\end{array}$ & & & & & & & & & & & & & & & \\
\hline & Vietnam & $\sqrt{ }$ & & $\sqrt{ }$ & & $\sqrt{ }$ & & & & & & & & & & \\
\hline \multirow[t]{3}{*}{ SEARO } & India & & & $\sqrt{ }$ & $\sqrt{ }$ & & 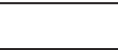 & & & $\sqrt{ }$ & & & $\sqrt{ }$ & $\sqrt{ }$ & $\sqrt{ }$ & \\
\hline & Indonesia & $\sqrt{ }$ & & $\sqrt{ }$ & $\sqrt{ }$ & $\sqrt{ }$ & $\sqrt{ }$ & $\sqrt{ }$ & $\sqrt{ }$ & $\sqrt{ }$ & $\sqrt{ }$ & $\sqrt{ }$ & $\sqrt{ }$ & $\sqrt{ }$ & $\sqrt{ }$ & $\sqrt{ }$ \\
\hline & Nepal & & & & $\sqrt{ }$ & $\sqrt{ }$ & & & & & & & & & & \\
\hline \multirow[t]{4}{*}{ EURO } & Kazakhstan & & & & & & $\sqrt{ }$ & $\sqrt{ }$ & $\sqrt{ }$ & & $\sqrt{ }$ & & & $\sqrt{ }$ & & \\
\hline & Kosovo & $\sqrt{ }$ & & $\sqrt{ }$ & & $\sqrt{ }$ & $\sqrt{ }$ & $\sqrt{ }$ & & & & & & & & \\
\hline & $\begin{array}{l}\text { Republic of } \\
\text { Moldova }\end{array}$ & $\sqrt{ }$ & & 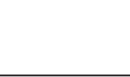 & & $\sqrt{ }$ & $\sqrt{ }$ & $\sqrt{ }$ & $\sqrt{ }$ & $\sqrt{ }$ & & & & $\sqrt{ }$ & & \\
\hline & Uzbekistan & $\sqrt{ }$ & & & & $\sqrt{ }$ & $\sqrt{ }$ & $\sqrt{ }$ & & $\sqrt{ }$ & $\sqrt{ }$ & $\sqrt{ }$ & & & & \\
\hline EMRO & Sudan & & $\sqrt{ }$ & $\sqrt{ }$ & $\sqrt{ }$ & $\sqrt{ }$ & $\sqrt{ }$ & & $\sqrt{ }$ & $\sqrt{ }$ & $\sqrt{ }$ & $\sqrt{ }$ & & $\sqrt{ }$ & & $\sqrt{ }$ \\
\hline \multirow[t]{2}{*}{ PAHO } & Peru & & $\sqrt{ }$ & & & & $\sqrt{ }$ & & & & & & & $\sqrt{ }$ & & \\
\hline & Nicaragua & & & & & & $\sqrt{ }$ & & & & & & & $\sqrt{ }$ & & \\
\hline
\end{tabular}

Note: Trainers $=$ Facilitators; $\mathrm{Cl}=$ Clinical Instructor 


\section{Figure 1: Other challenges to rapid acceleration of IMCI training - Results of Qualitative Data from} National IMCI Focal Persons / NPOs:

- Strategic differences regarding the role of IMCI:

- $\quad \mathrm{IMCl}$ is viewed as a vertical programme and not as a standard approach to managing sick children in health facilities (Uganda)

- Lack of consensus amongst partners regarding $\mathrm{IMCl}$ as a delivery vehicle for child health interventions. Only two agencies are currently providing support for facility-based IMCI training (Nigeria)

- Lack of political will / support:

- Lack of support by regional offices at $\mathrm{MOH}$ (Eritrea)

- Lack of an $\mathrm{MCH}$ office within the $\mathrm{MOH}$, and lack of clear division of roles and responsibilities (Kosovo)

- Lack of commitment from government (Nepal)

- Lack of resources (human, material, time) for IMCl implementation:

- Lack of fuel for transportation (Eritrea)

- Lack of funds for supervision after training (Eritrea, Ethiopia)

- Lack of funds and limited technical resources and funding for child health (Kosovo, Ghana, Cambodia, India)

- Low per diem

- Withdrawal of funders (Eritrea)

- Pressure of time for training (Kazakhstan)

- Facilitators being overloaded with work (Eritrea) / Lack of facilitators (Ghana, Moldova)

- Shortage of PHC doctors (Kosovo)

- Shortage of staff in health facilities (Kenya) / High staff turn-over (Ghana)

\section{- Poor reading ability of health workers (Vietnam)}

- Mismatch between training needs and what is available:

- The capacity of the existing education system is not enough for re-training of all health workers

- Lack of appropriate training sites (Cambodia)

- Mismatch between number of health workers needing to be trained and long duration of the course - Large country with a high number of health facilities and health workers (Indonesia, China)

- Other:

- Frequent changes in rules in the Ministry, resulting in discontinuity in work

- Existing deficiencies in health service provision (Kosovo)

- Lack of integration between information systems and IMCI (Kosovo)

- Informal payments (Kosovo)

- Drugs suggested by $\mathrm{IMCl}$ are not part of the drugs provided free of charge though the EDL (Kosovo)

Figure 1 Other challenges to rapid acceleration of IMCI training - Results from Qualitative Data from National Professional Officers/ Ministries of Health

and linking follow-up with ongoing routine supervision of services (Figure 4).

\section{Discussion}

Countries have identified several challenges to rapid scale-up of ICMT. The most concerning of these, and one that can possibly be addressed is the high cost of the course. Our previous paper highlighted the acceptability of standardised shortened IMCI courses that include participatory methodologies and adequate clinical practice, amongst selected country respondents [14]. However the effectiveness of shortened courses are still under further 


\section{FIGURE 2: HOW CHALLENGES TO SCALE UP IMCI HAVE BEEN ADDRESSED}

- Challenge: Strategic differences with regards to the role of IMCI / possible impact of IMCI:

- Through state planning meetings and the release of operational guidelines for $\mathrm{IMCl}$ implementation (India)

- The 2007-2009 medium-term expenditure framework has a budget line for child health and IMCI (Nigeria)

- Increasing advocacy for IMCI - planning to develop a child health policy (Kenya)

- A strategy for Maternal, Neonatal and Child Health has been developed and this recognises IMCI as one of the delivery vehicles for scaling up MCNH interventions (Nigeria). It is hoped that this strategy would facilitate the availability of and access to funds for $I \mathrm{MCl}$

- A monitoring and evaluation centre for child health has been developed, and a person appointed to monitor and evaluate $\mathrm{IMCl}$ (Moldova)

- One person has been assigned to oversee the IMCI team at national level (Eritrea)

- Sensitisation visits to district coordinators have been conducted at the beginning of the year prior to the development of the district programme of action (Eritrea). Planning with districts also occurs in Kenya

- A national training strategy was developed, in consultation with national and international partners (Kazakhstan)

- Financial challenges: Re-distribution of funds / lobbying for more funds:

- Other sources of funding have been utilised for supporting $\mathrm{IMCl}$ case management courses and supervision (Eritrea)

- Funds for IMCl have been taken from central government and training conducted at district level (Indonesia)

- Negotiations with donor organisations / other stakeholders are being held (Uzbekistan, Ghana)

- Lack of resources for IMCI implementation, especially lack of accommodation, time, training materials and human resources:

- Non-residential courses have been held where possible (Kenya)

- IMCl courses have been decentralised (Eritrea)

- Districts have been provided with a set of training materials to make them self-sufficient

- Exercises have been separated from the modules - modules are not taken home by participants and are thus re-used. This reduces the cost of printing modules, and is unlikely to affect quality (Uganda)

- Attempts have been made to shorten the duration of training to reduce cost (5-8 days): 5-days in China, Fiji, Indonesia, Kazakhstan, Nicaragua, Nigeria, Madagascar, Peru and Sudan; 6-days in Ethiopia, India, Indonesia, Kazakhstan, Madagascar, Nigeria. Niger and Uganda; 7-days in China, Egypt , Jordan, Nepal and Peru; 8-days in Egypt, India, Jordan and Kosovo

- Trained heath workers organise on the job training for untrained health workers (Uzbekistan)

- An abridged course for senior managers has been developed (Kenya, Ghana, Indonesia, Nicaragua and Madagascar)

- Computer-based training (6-days) has been developed (Kenya)

- District-based facilitators and clinical instructors have been trained (Uganda)

- Pre-service IMCI training has been expanded (India, Uzbekistan, Kazakhstan, Cambodia, Moldova)

- Poor reading ability of health workers:

- A 6-day abridged course and a simplified 5-day course have been developed - the 5-day course has little reading as health workers at operational level had difficulty reading (Nigeria)

- The duration of the course has been prolonged for health workers who have difficulty reading (Vietnam)

Figure 2 How challenges to scale up IMCI have been addressed.

investigation. Although a randomized trial in Zambia which compared performance of primary health workers trained in the 11-day course with those trained in the six-day abridged course - found no significant difference in 10 of 12 priority and 14 of 15 supplemental indicators assessing health worker performance [15], and although research in Kosovo found that assessment was either performed equally well or better by primary health care physicians trained in the 8-day course compared with those trained in the 11-day course [16], a systematic review of 


\section{Figure 3: $\quad$ Experiences of follow-up after training: Results of Qualitative Data from NPOs, National IMCI Focal Persons (Ministries of Health), Course Directors and IMCI Trainees}

\section{Facilitator/Course director opinions:}

\section{Positive opinions:}

- "They like it. Opportunity as a second training. Not like an exam"

- "IMCl without follow-up means that ones money spent on training has been lost"

- "Essential and necessary that health workers implement in routine work. Helps identify gaps"

- "Interest in training quality, application of skills and knowledge by health workers"

- "Part of the training"

- "One of the important components, and needs to be strictly done to improve performance"

\section{Negative opinions / Barriers / Impression that there is no way out:}

- "Participants feel supervisors will police them"

- "How can it be established as a regular part of IMCI"

- "Lack of operational funds"

- "Follow-up is difficult"

\section{Opinions of IMCI Trainees:}

\section{Positive opinions}

- "Very important"

- "This is a good thing - we need it frequently"

- "Very useful"

- "Should be conducted more regularly"

- "Provide technical support"

\section{Despondency}

- "Not sure whether they will ever come for follow-up"

- "Important but frequently not done"

- "Important but not done routinely"

- "Who will do this as supervisors are inferior in their skills"

\section{Negative opinions}

- "I don't like these visits and their monitoring"

- "I hope I get it right - (it's almost like policing)"

Figure 3 Experiences of follow-up after training: Results of Qualitative Data from National Professional Officers, Ministries of Health, Course Directors and IMCI Trainees.

the effectiveness of shortening Integrated Management of Childhood Illness guidelines training found that the standard in-service IMCI training course is somewhat more effective than short training; although the magnitude of the difference was unclear $(-3$ to $+18 \%$-points) [17]. Thus shortening duration of training as a means to reduce cost and facilitate scale-up of IMCI still needs to be further investigated.
Health Systems constraints, such as transport or supervision, to scale-up and follow-up after training have been described in other studies: Bryce et.al found that four of the five IMCI multi-country evaluation countries (the exception is Tanzania) had difficulties in expanding the strategy at national level while maintaining adequate intervention quality [18]. They found that the full weight of health system limitations on IMCI 


\section{FIGURE 4: SPECIFIC SUGGESTIONS ON FOLLOW-UP AFTER ICMT}

- "Must be seen as part of IMCI training"

- "Very important for strengthening practical skills and establishing technical support"

- "Emphasise and plan follow-up before a course is planned"

- "Link with ongoing supervision / Aim for integrated follow-up and supervision / Supervisors need to strengthen this"

Figure 4 Specific suggestions on follow-up

implementation was not appreciated at the outset, and only after investigation was it clear that finding solutions to larger problems such as political commitment, human resources, financing, integrated or at least coordinated programme management, and effective decentralization are essential underpinnings of successful efforts to reduce child mortality.

Given this information, and acknowledging that health systems in many countries where IMCI would be most beneficial are weak, almost all IMCI focal persons/NPOs suggested that the approach to IMCI training should be reviewed to avoid nominal implementation: the combination of a long, costly course to be rolled-out in countries with critical health system constraints such as staff shortages may only cripple the reputation of a strategy that could potentially be one of the key interventions to reducing infant and child mortality rates and meeting the fourth Millennium Development Goal.

This paper does not thus raise new issues about challenges to IMCI scale-up; in fact the follow-up recommendations echo the 1998 Follow-Up Guidelines in the IMCI information pack [1], signifying little change since 1998. However this paper is important for three reasons: Firstly this is the first paper to describe challenges to IMCI scale up based on data from all six WHO regions, providing a more global perspective almost twelve years after IMCI was implemented. Thus the paper serves to benchmark the status of IMCI implementation and challenges to scale-up globally. Secondly this paper describes challenges through the eyes of several cadres of health workers from national level to sub-district level. Thirdly the paper presents the results of quantitative and qualitative data on challenges to IMCI scale-up: the latter corroborates the former and of grave concern is that the qualitative data highlights a sense of despondency that surrounds aspects of IMCI scale-up e.g. follow-up after ICMT. This underscores the urgency needed to overcome barriers to IMCI implementation, especially if IMCI is mooted as a key strategy to accelerate progress towards MDG4.
Several approaches to overcoming barriers to IMCI implementation are currently being tested: Since 2009 IMCI Computerised Adaptation and Training Tool (ICATT) - an innovative software technology to support the adaptation of generic IMCI guidelines at national and sub-national levels - has been tested in several settings including Tanzania, Peru, Indonesia and East Java [19]. The course was tested in a classroom setting in Tanzania and Peru and then as distance learning material in Tanzania, Indonesia and East Java. The distance-based course involves three one-day face to face facilitator-participants interactions and two self-learning period in between. During these self-learning periods tutors keep in weekly contact with participants. Early experiences show that difficulties associated with participants' computers and running the ICATT player should be anticipated; facilitators need to be carefully selected and perhaps need to be comfortable with IMCI materials before the course; course duration was too long (56-58 days) and the first contact session was too demanding on facilitators. ICATT is still undergoing further refinement but could be an innovative way to reduce the burden of training both financially and from a human resource perspective. Furthermore in Tanzania D-Tree International has been working to improve the use of the IMCI protocols through the development of an electronic version of IMCI (eIMCI) for use on cell phones and other mobile devices [20]. The software runs on a PDA or mobile phone and guides health workers step-by-step through the full IMCI assessment, classification and treatment plan. The software was designed for ease of use and the training of clinicians took less than 1 hour in all cases. D-Tree have piloted e-IMCI in rural Tanzania where initial results indicate that clinicians were enthusiastic about e-IMCI and more closely adhere to the IMCI protocol when using e-IMCI than without it. A large scale study is currently underway to validate these initial findings that e-IMCI leads to improved adherence to the IMCI protocols compared to the conventional use of IMCI, and to examine the cost 
and cost-effectiveness of e-IMCI compared to the conventional paper based IMCI and routine ICMT. Furthermore in South Africa a distance IMCI project is being implemented as a major alternative to ICATT and eIMCI.

\section{Conclusions}

Financial challenges to ICMT scale-up and follow-up after training, and human resource shortages (in number or skill) are critical bottle necks to ICMT scale-up. If IMCI is accepted as one of the key strategies to meet MDG4 then ways to reduce cost of ICMT and to integrate follow-up into routine health system organization and functioning should urgently be identified and supported. Cost-effective ways of implementing ICMT need to be explored, including reviewing the competencies, reviewing training approaches such as shortening duration for specific core IMCI competencies, or enhancing on the job-training or distance learning and using technologies such as computer-based training or mobile phone-based training.

\section{Abbreviations}

IMCI: Integrated Management of Childhood IIIness Strategy; ICMT: IMCI Case Management Training; WHO: World Health Organisation; UNICEF: United Nations Children's Fund;

\section{Acknowledgements}

Dr Elizabeth Mason for support during the design of the survey The WHO regional offices

All IMCI focal persons, national programme officers, course directors, facilitators and trainees who participated in the review

\section{Author details}

${ }^{1}$ Health Systems Research Unit, Medical Research Council, 1 Soutpansberg Road, Pretoria, 0001 Pretoria, South Africa. ${ }^{2}$ Department of Child and Adolescent Health and Development (CAH), World Health Organisation, Avenue Appia 20, 1211 Geneva 27, Switzerland.

\section{Authors' contributions}

AEG and LMM conceptualized and designed the survey. LMM (WHO) selected the countries and facilities and distributed the questionnaire through IMCI networks.

AEG gathered the data, analysed and interpreted the data and drafted the manuscript.

AEG and LMM contributed to the manuscript finalization. All authors read and approved the final manuscript.

\section{Competing interests}

The authors declare that they have no competing interests.

Received: 21 January 2011 Accepted: 27 June 2011

Published: 27 June 2011

\section{References}

1. World Health Organisation, UNICEF: IMCI information package. 1999 [http://www.who.int/child_adolescent_health/documents/chs_cah_98_1a/ en/, Accessed 10 May 2010.

2. Schellenberg J, Adam T, Mshinda H, Masanja H, Kabadi G, Mukasa O, John T, Charles S, Nathan R, Wilczynska K, Mgalula L, Mbuya C, Mswia R, Manzi F, de Savigny D, Schellenberg D, Victora C: Effectiveness and cost of facility-based Integrated Management of Childhood Ilness (IMCI) in Tanzania. the Lancet 2004, 364(30 October):1583-1593.

3. Gouws E, Bryce J, Habicht JP, Amaral J, Pariyo G, Schellenberg JA, Fontaine O: Improving antimicrobial use among health workers in firstlevel facilities: results from the multi-country evaluation of the
Integrated Management of Childhood Illness strategy. Bulletin of the World Health Organization 2004, 82(7):509-515.

4. Amaral J, Leite AJ, Cunha AJ, Victora CG, Amaral J, Leite AJ, Cunha AJ, Victora CG: Impact of IMCI health worker training on routinely collected child health indicators in Northeast Brazil. Health Policy \& Planning 2005, 20(Suppl 1):i42-i48.

5. Arifeen S, Blum L, Hoque D, Chowdhury E, Khan R, Black R, Victora C, Bryce J: Integrated Management of Childhood Illness (IMCI) in Bangladesh: early findings from a cluster-randomised study. the Lancet 2004, 364:1595-1602.

6. Arifeen SE, Bryce J, Gouws E, Baqui AH, Black RE, Hoque DM, Chowdhury EK, Yunus M, Begum N, Akter T, Siddique A: Quality of care for under-fives in first-level health facilities in one district of Bangladesh. Bulletin of the World Health Organization 2005, 83(4):260-267.

7. Bryce J, Victora CG, Habicht JP, Black RE, Scherpbier RW: Programmatic pathways to child survival: results of a multi-country evaluation of Integrated Management of Childhood Illness. Health Policy \& Planning 2005, 20(Suppl 1):i5-i17.

8. Bryce J, Victora CG, Habicht JP, Vaughan JP, Black RE, Bryce J, Victora CG, Habicht JP, Vaughan JP, Black RE: The multi-country evaluation of the integrated management of childhood illness strategy: lessons for the evaluation of public health interventions. American Journal of Public Health 2004, 94(3):406-415.

9. Arifeen S, Blum L, Hoque D, Chowdhury E, Khan R, Black R, Victora C, Bryce J: Integrated Management of Childhood Illness (IMCI) in Bangladesh: early findings from a cluster-randomised study. Lancet 2004, 364(9445):1595-1602, [see comment].

10. Gilroy K, Winch PJ, Diawara A, Swedberg E, Thiero F, Kane M, Daou Z, Berthe Z, Bagayoko A: Impact of IMCI training and language used by provider on quality of counseling provided to parents of sick children in Bougouni District, Mali. Patient Education \& Counseling 2004, 54(1):35-44.

11. Gwatkin DR, Gwatkin DR: IMCl: what can we learn from an innovation that didn't reach the poor? Bulletin of the World Health Organization 2006, 84(10):768, [comment].

12. Horwood C, Vermaak K, Rollins N, Haskins L, Nkosi P, Qazi S: An evaluation of the quality of $\mathrm{IMCl}$ assessments among IMCI Trained health workers in South Africa. PLOS ONE 2009, 4(6)::5937.

13. Horwood C, Voce A, Vermaak K, Rollins N, Qazi S: Experiences of Training and implementation of integrated management of childhood illnesss (IMCI) in South Africa: a quaitative evaluation of the IMCI case management training course. BMC Paediatrics 2009, 9(62).

14. Goga A, Muhe L, Forsyth K, Chopra M, Aboubaker S, Martines J, Mason E: Results of a multi-country exploratory survey of approaches and methods for IMCl case management training. Health Research Policy and Systems 2009, 7(18).

15. Mwinga K, Siziya S, Kasungami DKP, Tambatamba B: Comparative study of two types of IMCI Case Management courses in Zambia. Technical Consultation of $\mathrm{IMCl}$ inservice and preservice training approaches and methods 2007. Geneva; 2007.

16. Skender S: A comparison of standard training ( 11 days) with adapted 8 days IMCI training in Kosovo. University of Copenhagen., Department of International Health, Institute of Public Health; 2007.

17. Rowe A, Rowe S, Holloway K, Ivanovska V, Muhe L, Lambrechts T: A systematic review of the effectiveness of shortening Integrated Management of Childhood IIIness guidelines training: Final Report. WHO; 20092009.

18. Bryce J, Victora C, Habicht J, Black R, Scherpbier R: Programmatic pathways to child survival: results of a multi-country evaluation of Integrated Management of Childhood Illness. Health Policy and Planning 2005, , supplement 1: i5-117.

19. World Health Organisation: IMCI Computerised Adaptation and Training Tool.[http://www.icatt-training.org/], Access 19 May 2010.

20. D-TREE International: e-IMCI. [http://www.d-tree.org/index.php?pid=62], Accessed 20 May 2010.

Pre-publication history

The pre-publication history for this paper can be accessed here: http://www.biomedcentral.com/1471-2458/11/503/prepub

doi:10.1186/1471-2458-11-503

Cite this article as: Goga and Muhe : Global challenges with scale-up of the integrated management of childhood illness strategy: results of a multi-country survey. BMC Public Health 2011 11:503. 